\title{
Monoclonal Antibody Therapy and Progressive Multifocal Leukoencephalopathy
}

Progressive multifocal leukoencephalopathy (PML) is an opportunistic disease caused by reactivation of latent human JC polyomavirus that causes infection and lysis of oligodendrocytes resulting in demyelination. Progressive multifocal leukoencephalopathy was initially recognized in patients with lymphoproliferative disorders and subsequently about $85 \%$ of cases have occurred in patients with human immunodeficiency virus infection. In the era of highly active antiretroviral therapy (HAART), the incidence of PML has decreased. ${ }^{1}$ Natalizumab (Tysabri, Biogen Idec / Elan Pharmaceuticals) is a recombinant humanized monoclonal antibody against $\alpha_{4}$ integrins ${ }^{2}$ that has been used for the therapy of multiple sclerosis. Natalizumab was developed in order to inhibit the transmigration of $\mathrm{T}$ cells from the circulation into the brain parenchyma, ${ }^{2}$ and it increases circulating B cells and pre-B cells. ${ }^{3}$ This antibody has efficacy for the treatment of relapsing-remitting multiple sclerosis. ${ }^{4}$ On February 28, 2005 natalizumab was withdrawn from the market ${ }^{5}$ after reports that two patients with multiple sclerosis in clinical trials developed PML associated with receiving natalizumab and interferon beta- $1 \mathrm{a}^{6,7}$ and an additional case of PML occurred in a patient receiving natalizumab for Crohn's disease. ${ }^{8}$ Natalizumab was remarketed in June 2006 in the United States and Europe ${ }^{9}$ and subsequently came onto the market in Canada in October 2006.

We have learned that the incidence of PML increases with the duration of natalizumab use and is proportional to the duration of exposure in the first three years of use. ${ }^{9}$ In patients who were treated with natalizumab for a mean of 17.9 months (monthly doses), the incidence of confirmed PML is nearly one case per 1000 patients (95\% CI $0.2-2.8$ per 1000). ${ }^{10}$ As of May 4, 2011 there have been 124 confirmed cases of PML worldwide in patients who have received natalizumab, including 69 in the European Union, 49 in the USA, and 6 in the rest of the world; $19 \%$ of these PML patients have died. ${ }^{11}$ Only very recently has the first patient been diagnosed in Canada in Quebec (Dr. Anthony Traboulsee, personal communication). In addition, many cases of PML have been reported in association with therapy with rituximab, ${ }^{12}$ but here the indication is an important confounder. Prior immunosuppressive therapy is also a risk factor for the development of PML. ${ }^{13}$ Cognitive changes are often prominent in the presentation, and there may also be motor, language, and visual symptoms. ${ }^{9}$ New magnetic resonance (MR) lesions are consistently seen, typically in areas not previously affected by multiple sclerosis. Gadolinium enhancement has been observed in almost half of patients, ${ }^{9}$ whereas enhancement is usually minimal or absent in PML in most other settings. Evaluation of cerebrospinal fluid (CSF) for JC virus using polymerase chain reaction (PCR) has high specificity (96-99\%), but sensitivities range from 57 to $90 \% .{ }^{1}$ Because viral loads are often low in CSF, high sensitivity PCR assays are necessary ${ }^{9}$ and brain biopsy may be needed for diagnostic confirmation. ${ }^{1}$ Patients receiving natalizumab therapy need close clinical observation and serial MR brain imaging. Therapy of natalizumab-associated PML usually requires removal of the drug from the circulation by plasma exchange or immunoabsorption..$^{9,14}$ Frequently, neurological immune reconstitution inflammatory syndrome (IRIS) develops, which is characterized by inflammatory reaction at sites of PML lesions, and corticosteroids are usually given in order to reduce the inflammatory response..$^{9,14}$

In the current issue of the Journal, Keene et $\mathrm{al}^{15}$ present worldwide data on reported cases of PML after exposure to therapy with monoclonal antibodies; through April 15, 2010 they found a total of 182 reports with none from Canada. The 182 reports compare with only 95 case reports in the medical literature, indicating the importance of adverse events databases. However, for natalizumab there were 32 cases in the databases versus 28 cases in the medical literature, likely reflecting the intense attention related to the first cases reported from multiple sclerosis clinical trials and on a patient with Crohn's disease published in the New England Journal of Medicine. ${ }^{6-8}$ The vast majority of reports have occurred after the products have been marketed rather than during pre-market clinical trials. Canada Vigilance is the national database of adverse events in Canada, which is operated by Health Canada, whereas the World Health Organization has an international database for monitoring adverse events that is obtained from national and regional sources. As Keene et $\mathrm{al}^{15}$ point out, information from these databases is essential for risk mitigation, which may include changes to the product monograph, special training of practitioners, need for informed consent, development of patient registries, and, rarely, withdrawal of market authorization. When natalizumab finally entered the market in Canada, a variety of risk mitigation strategies were employed.

Three or more cases of PML have been reported with seven different monoclonal antibodies, but, as Keene et al indicate, the indications and concomitant medications are important confounders. ${ }^{15}$ For example, both rituximab and alemtuzumab have indications for therapy of chronic lymphocytic leukemia and non-Hodgkin's lymphoma and these disorders are associated with an increased risk of developing PML, which is partially related to the use of chemotherapy. This makes it difficult to determine causation. However, rituximab therapy has been associated with six cases of PML in patient with rheumatoid arthritis, which has led to enhanced product labeling in Canada as a risk mitigation strategy. ${ }^{15}$ In April 2009 there was a 
voluntary phased withdrawal of efalizumab (targets the $\alpha$ subunit of leukocyte function antigen-1 that binds to the intracellular adhesion molecule on antigen-presenting cells ${ }^{14}$ ), which was used for therapy of chronic plaque psoriasis, from the market as a result of reports of three cases of PML. ${ }^{16}$ Clearly, adverse event monitoring and maintenance of adverse events databases are very important with monoclonal antibody therapy.

Progressive multifocal leukoencephalopathy was a rare disease in the past. However, HIV infection and monoclonal antibody therapy have greatly increased the incidence of PML in specific patient groups, which underscores the importance of close monitoring of susceptible patients and gaining a better understanding of the biology of the JC polyomavirus. In the future, there is hope that JC serology may prove helpful for risk stratification for the identification of patients at low risk for developing PML with data showing that all pre-PML serology samples were seropositive and none were seronegative. ${ }^{17}$ However, as a result of conflicting studies, ${ }^{18,19}$ it still remains unsettled whether viral reactivation occurs in multiple sclerosis patients on natalizumab therapy and further studies are needed.

\section{Alan C. Jackson University of Manitoba Winnipeg, Manitoba, Canada}

\section{REFERENCES}

1. Engsig FN, Hansen AB, Omland LH, et al. Incidence, clinical presentation, and outcome of progressive multifocal leukoencephalopathy in HIV-infected patients during the highly active antiretroviral therapy era: a nationwide cohort study. J Infect Dis. 2009;199:77-83

2. Rice GP, Hartung HP, Calabresi PA. Anti-alpha4 integrin therapy for multiple sclerosis: mechanisms and rationale. Neurology. 2005;64:1336-42.

3. Krumbholz M, Meinl I, Kumpfel T, Hohlfeld R, Meinl E. Natalizumab disproportionately increases circulating pre-B and B cells in multiple sclerosis. Neurology. 2008;71:1350-4.

4. O'Connor PW. Use of natalizumab in multiple sclerosis patients. Can J Neurol Sci. 2010;37:98-104.

5. Adelman B, Sandrock A, Panzara MA. Natalizumab and progressive multifocal leukoencephalopathy. N Engl J Med. 2005;353:432-3.
6. Langer-Gould A, Atlas SW, Green AJ, Bollen AW, Pelletier D. Progressive multifocal leukoencephalopathy in a patient treated with natalizumab. N Engl J Med. 2005;353:375-81.

7. Kleinschmidt-DeMasters BK, Tyler KL. Progressive multifocal leukoencephalopathy complicating treatment with natalizumab and interferon beta-1a for multiple sclerosis. N Engl J Med. 2005;353:369-74.

8. Van AG, Van RM, Sciot R, et al. Progressive multifocal leukoencephalopathy after natalizumab therapy for Crohn's disease. N Engl J Med. 2005;353:362-8.

9. Clifford DB, De Luca A, Simpson DM, Arendt G, Giovannoni G, Nath A. Natalizumab-associated progressive multifocal leukoencephalopathy in patients with multiple sclerosis: lessons from 28 cases. Lancet Neurol. 2010;9:438-46.

10. Yousry TA, Major EO, Ryschkewitsch C, et al. Evaluation of patients treated with natalizumab for progressive multifocal leukoencephalopathy. N Engl J Med. 2006;354:924-33.

11. Biogen Idec (2011) Tysabri PML monthly update - May 2011.

12. Carson KR, Evens AM, Richey EA, et al. Progressive multifocal leukoencephalopathy after rituximab therapy in HIV-negative patients: a report of 57 cases from the Research on Adverse Drug Events and Reports project. Blood. 2009;113:4834-40.

13. Sandrock A, Hotermans C, Richman S, et al. Risk stratification for progressive multifocal leukoencephaloathy (PML) in MS patients: role of prior immunosuppressant use, natalizumabtreatment duration, and anti-JCV antibody status (Abstract). Neurology. 2011; 76(Suppl 4):A278.

14. Tan CS, Koralnik IJ. Progressive multifocal leukoencephalopathy and other disorders caused by JC virus: clinical features and pathogenesis. Lancet Neurol. 2010;9:425-37.

15. Keene DL, Legare C, Taylor E, Gallivan J, Cawthorn GM, Vu D. Monoclonal antibodies and progressive multifocal leukoencephalopathy. Can J Neurol Sci. 2011;38(4):565-71.

16. Korman BD, Tyler KL, Korman NJ. Progressive multifocal leukoencephalopathy, efalizumab, and immunosuppression: a cautionary tale for dermatologists. Arch Dermatol. 2009;145: 937-42.

17. Gorelik L, Lerner M, Bixler S, et al. Anti-JC virus antibodies: implications for PML risk stratification. Ann Neurol. 2010;68: 295-303.

18. Chen Y, Bord E, Tompkins T, et al. Asymptomatic reactivation of $\mathrm{JC}$ virus in patients treated with natalizumab. $\mathrm{N}$ Engl J Med. 2009;361:1067-74.

19. Jilek S, Jaquiery E, Hirsch HH, et al. Immune responses to JC virus in patients with multiple sclerosis treated with natalizumab: a cross-sectional and longitudinal study. Lancet Neurol. 2010;9: 264-72. 